\title{
PERSEPSI DAN DILEMA PUSAT PELAYANAN KESEHATAN SEBAGAI KAWASAN BEBAS ROKOK
}

\author{
I W. Sudiadnyana, I G.W. Darmadi, I W. Suarta Asmara \\ Dosen Poltekkes Denpasar Jurusan Kesehatan Lingkungan \\ Sudiadnyana67@yahoo.co.id
}

\begin{abstract}
Cigarette consumption problems and health impact of ever greater world, and so do in Indonesia. Policy Health Minister of Republic Indonesia call upon puskesmas to specified as free smoking area, not yet getting many attention of health care management. Puskesmas Kediri I Tabanan still now not yet been spicified as free smoking area, so that employees and visitor also there still smoking in puskesmas area. The objective of study was evaluated the readness of health officer to realize puskesmas as free smoking area. Research method was qualitative design with Rapid Asessment Procedure (RAP). Information as responder taken away from puskesmas health officer and visitor. Data collection with in-dept interviews, observation and documentation studies. Final data analysis using theme analysis. Results of study was showed perception of health officer to danger smoke to health no doubt again. Puskesmas health officer was agrred if puskesmas specified to free smoking area, and if this matter realized its estimeted no resistence either health officer and also visitor. Conclusion of this study was health officer basicaly have ready for realizing puskesmas as free smoking area. Suggested to management of puskesmas, so that immediately realize Puskesmas Kediri I as free smoking area.
\end{abstract}

Keywords : Free smoking area, perception

\begin{abstract}
ABSTRAK. Peningkatan konsumsi rokok dan dampaknya bagi kesehatan menjadi masalah kesehatan dunia, demikian juga di Indonesia. Kebijakan Menteri Kesehatan yang menetapkan Puskesmas sebagai kawasan bebas rokok, belum sepenuhnya ditindaklanjuti oleh manajemen pelayanan kesehatan. Puskesmas Kediri I Tabanan sampai saat ini belum ditetapkan sebagai kawasan bebas rokok, sehingga masih ada karyawan dan pengunjung yang merokok di areal puskesmas. Penelitian ini bertujuan untuk mengevaluasi kesiapan tenaga puskesmas untuk mewujudkan puskesmas sebagai kawasan bebas rokok. Penelitian menggunakan metoda kualitatif dengan pendekatan Rapid Assesement Procedure (RAP). Informan sebagai responden adalah tenaga kesehatan dan pengunjung puskesmas. Pengumpulan data dilakukan dengan wawancara mendalam, observasi dan studi dokumentasi. Analisis data akhir menggunakan analisis tema. Hasil penelitian menunjukkan bahwa persepsi petugas kesehatan terhadap bahaya rokok sangat positif, walaupun masih ada karyawan yang sampai saat ini belum bisa berhenti merokok. Untuk mewujudkan puskesmas sebagai kawasan bebas rokok perlu kesiapan petugas dan pengunjung puskesmas. Kesimpulan dari penelitian ini menunjukkan bahwa petugas kesehatan pada dasarnya siap mewujudkan puskesmas sebagai kawasan bebas rokok. Disarankan agar manajemen puskesmas segera mewujudkan puskesmas sebagai kawasan bebas rokok.
\end{abstract}

Kata kunci : kawasan bebas rokok, persepsi 


\section{Pendahuluan}

Rokok adalah masalah kesehatan dunia, sekitar $70 \%$ kematian penduduk pada negara berkembang disebabkan oleh rokok. Kematian akibat rokok di Indonesia menduduki peringkat ketiga dunia setelah China dan India. Selama tahun 2007, sebanyak 1.127 orang Indonesia meninggal setiap hari akibat rokok. ${ }^{1}$ Lebih dari 43 juta anak Indonesia terpapar asap rokok sebagai perokok pasif. ${ }^{2}$

Perilaku merokok remaja Bali hasil penelitian Hadi, dkk. ${ }^{3}$, menyatakan bahwa 24,3\% remaja Bali merokok karena diajak teman dan $92,1 \%$ karena mereka sering berada di antara orang merokok. Lebih jauh tentang sikap terhadap kawasan tanpa rokok, perokok setuju diterapkan pada tempat tertentu yaitu rumah sakit, sekolah dan tempat ibadah.

Menurut WHO, petugas kesehatan harus menjadi role model bagi masyarakat, karena dianggap paling tahu tentang kesehatan. Oleh karena itu, bila petugas kesehatan masih merokok, program pencegahan rokok di Indonesia akan sulit dilaksanakan. Larangan merokok pada sarana kesehatan sudah dicanangkan dengan adanya Instruksi Menteri Kesehatan No. 459 tahun 1999, tentang kawasan bebas rokok pada sarana kesehatan. Melalu instruksi ini sarana pelayanan kesehatan termasuk pendidikan dan latihan agar menjadikan lingkungan tempat kerja sebagai kawasan bebas asap rokok, menyerukan kepada petugas kesehatan untuk berhenti merokok dan sekaligus menjadi panutan bagi masyarakat. ${ }^{4}$

Hasil pengamatan peneliti sebagai studi pendahuluan, sampai saat ini Puskesmas Kediri I belum menerapkan areal puskesmas sebagai kawasan bebas rokok. Beberapa pegawai atau petugas kesehatan masih kelihatan merokok terutama pada saat santai atau sedang beristirahat. Walaupun belum ada data pasti berapa jumlah pegawai puskesmas yang merokok, tapi paling tidak dengan tidak diberlakukannya kawasan bebas rokok, menyebabkan pegawai yang mau merokok tidak mempunyai tempat yang khusus. Kondisi ini yang menyebabkan lingkungan puskesmas terkena polusi akibat asap rokok. Hal ini lebih diperberat lagi oleh asap rokok yang berasal dari pengunjung puskesmas.

Tujuan dari penelitian ini adalah mengkaji secara mendalam mengenai persepsi dan dilema pusat pelayanan kesehatan sebagai kawasan bebas rokok.

\section{Metode Penelitian}

Jenis penelitian yang digunakan adalah kualitatif, dengan rancangan rapid assessment procedure. ${ }^{5}$ Jumlah informan 
keseluruhan dalam penelitian ini adalah 14 orang, dengan rincian 2 orang dari unsur pimpinan puskesmas, 4 orang tenaga fungsional, 4 orang tenaga administrasi dan 4 orang pengunjung puskesmas. Pengumpulan data utama mengenai pesepsi petugas kesehatan terhadap kawasan bebas rokok dilakukan dengan wawancara mendalam (indepth interview) dengan pertimbangan peneliti ingin menggali informasi sebanyak-banyaknya dari informan terkait dengan tujuan penelitian. ${ }^{6}$ Untuk keperluan triangulasi, peneliti juga melakukan pengumpulan data dengan cara observasi dan studi dokumen.

Analisis data dilakukan bersamaan dengan pengumpulan data (ongoing analysis). Data dari informan direduksi menjadi informasi yang bermakna dengan melakukan coding. ${ }^{7}$ Analisis data akhir menggunakan analisis tema yaitu data yang didapat dari informan dikelompokkan ke dalam suatu tema. ${ }^{8}$

\section{Hasil Penelitian dan Pembahasan}

Persepsi petugas kesehatan tentang bahaya rokok bagi kesehatan

$\begin{array}{cll}\text { Sebagian } & \text { besar } & \text { responden } \\ \text { berprofesi pada bidang } & \text { kesehatan, }\end{array}$ mempunyai persepsi positif tentang bahaya rokok bagi kesehatan. Umumnya informasi tentang bahaya rokok, mereka 20 peroleh saat responden menuntut ilmu di bidang kesehatan. Informasi tentang bahaya rokok yang lebih lengkap mereka terima setelah bekerja di pelayanan kesehatan. Hasil wawancara dengan responden menyatakan bahwa bahaya rokok bagi kesehatan pada dasarnya sudah tidak diragukan lagi. Beberapa responden di antaranya menyatakan :

“...menurut saya yang pertama itu, kanker pak.... kanker paru dan banyak lagi efek samping lainnya" (K-2)

"Oh ya... seperti pada pembungkus rokok... bahwa rokok dapat menimbulkan hipertensi, kanker dan apa lagi,,, ya gangguan janin dan kehamilan" $(K-1)$

"Emm...batuk-batuk dan gangguan nafas... jadi pendek dan mudah lelah" $(K-10)$

Terkait bahaya rokok terhadap lingkungan sekitar, juga telah disadari oleh responden. Kepulan asap rokok di lingkungan sekitar dapat juga dihirup oleh orang yang tidak merokok disebut sebagai perokok pasif. Responden yang merokokpun menyadari akan hal tersebut, dengan sedikit rasa malu responden menyatakan :

“....lingkungan di sekitar....karena merokok juga mempengaruhi orang yang tidak merokok. Mereka juga terkena kontaminasi... yang juga sama bahayanya...dengan perokok" (K-8)

"Kan tidak semua orang suka rokok pak...apalagi ibuk-ibuk, kalau saya 
merokok di ruangan.... asapnya mereka hirup juga, bisa marah dia" $(K-5)$

Berdasarkan hasil observasi di ruang tunggu pasien/ pengunjung puskesmas, memang tidak tersedia asbak. Keadaan ruangan relatif bersih dan tidak ada abu atau sisa puntung rokok di bawah kursi. Hal ini mengindikasikan pengunjung sangat jarang merokok di ruangan ini. Walaupun responden mengakui bahwa pernah ada pengunjung yang merokok, tetapi frekuensinya sangat jarang.

"Pengunjung yang merokok itu ...jarang, bahkan sangat jarang...kalau sebulannya itu..., paling ada satu atau dua orang saja” (K-6)

Jumlah karyawan Puskesmas Kediri I Tabanan yang biasa merokok adalah 3 orang semuanya laki-laki. Sampai saat ini mereka belum bisa berhenti merokok. Kalau mereka terpaksa merokok di areal puskesmas, biasanya dilakukan pada suatu tempat atau sudut ruangan depan gudang yang agak jauh dari kegiatan pelayanan kesehatan. Faktanya memang orang yang biasa merokok, susah untuk berhenti, karena rokok mengandung nikotin yang membuat perokok selalu ingin merokok lagi atau ketagihan. ${ }^{8}$

Persepsi petugas kesehatan tentang kawasan bebas rokok
Secara umum petugas kesehatan mempunyai persepsi yang positif bila Puskesmas Kediri I Tabanan ditetapkan sebagai kawasan bebas rokok. Logikanya penolakan akan muncul dari petugas kesehatan yang biasa merokok, karena ada kemungkinan mereka akan kehilangan tempat untuk menikmati rokok. Dengan adanya pemahaman akan bahaya rokok bagi kesehatan dan kesadaran mereka sebagai petugas kesehatan, mereka tidak keberatan bila puskesmas ditetapkan sebagai kawasan bebas rokok. Beberapa petikan terhadap hasil wawancara responden sebagai berikut :

"Setuju... sesuai arahan induk kami di dinas kesehatan... tolong teman-teman di puskesmas...agar memberi contoh tidak merokok, baik pada pasien maupun pengunjung puskesmas” $(K-2)$

"Kalau sudah kebijakan puskesmas... saya setuju pak, walaupun saya perokok. Bagi saya tidak masalah... kalau di sini nggak boleh... ya saya kan bisa keluar... di warung...di luar puskesmas" $(K-3)$

Walaupun secara persepsi petugas kesehatan setuju menjadikan puskesmas sebagai kawasan bebas rokok, namun sampai saat ini belum ada realisasi baik dalam bentuk perencanaan maupun operasionalnya. Pihak manajemen puskesmas menyadari bahwa penetapan puskesmas sebagai kawasan bebas rokok akan menuntut kesiapan dan ketersediaan 
sumber daya dan biaya. Disamping itu belum ada petunjuk atau instruksi langsung dari dinas kesehatan sebagai pedoman dalam pelaksanaannya.

Penetapan puskesmas sebagai kawasan bebas rokok dalam pelaksanaannya diperkirakan tidak banyak mengalami hambatan. Disamping karena jumlah karyawan yang merokok sedikit sekitar 6\%, juga didukung oleh kesadaran pengunjung bahwa puskesmas sebagai tempat berobat semestinya bebas asap rokok. Hasil wawancara terhadap pengunjung menyatakan :

"sebaiknya begitu... puskesmas itu...ya seharusnya bebas rokok, sebagai contoh... sehingga yang berobat tidak tambah sakit”(P-4)

“meski saya perokok, kalau ke puskesmas kan tidak... malu sama petugas dan pengunjung yang lain” $(P-2)$

Di sisi lain ada juga responden yang menyatakan bahwa sebelum puskesmas ditetapkan sebagai kawasan bebas rokok, perlu ada pengkajian yang mendalam tentang keterlibatan staf puskesmas dalam monitoring maupun evaluasinya. Terkait dengan sanksi bagi yang melanggar tidak banyak dicetuskan karena ada perasaan tidak enak atau enggan karena yang melanggar adalah teman sekerja. Berikut pernyataan responden sebagai berikut :

"Ya apa.. ya... paling tidak, berupa teguran jangan merokok disini... sama teman ya begitu saja..”(K-9)

"Saya kira sanksi ini... agak susah sih pak... upaya saya yah...untuk mengurangi rokok... agar kita semua menjadi lebih sehat” $(K-7)$

Mengacu pengembangan puskesmas di era desentralisasi, memberikan kewenangan secara mandiri kepada puskesmas dalam penyelenggaraan perencanaan, pelaksanaan dan evaluasi pembangunan kesehatan di wilayah kecamatan. ${ }^{10}$ Dengan kewenangan seperti itu memungkinkan manajemen Puskesmas Kediri I dapat menetapkan program puskesmas sebagai kawasan bebas rokok, tanpa harus menunggu instruksi dari dinas kesehatan kabupaten.

\section{Simpulan dan Saran}

Persepsi petugas kesehatan terhadap bahaya rokok sangat positif, walaupun masih ada karyawan laki-laki perokok yang sampai saat ini belum bisa berhenti merokok. Demikian juga persepsi terhadap puskesmas sebagai kawasan 
bebas rokok juga positif. Untuk mewujudkan program puskesmas sebagai kawasan bebas rokok memerlukan pertimbangan dan kajian secara teknis maupun manajerial.

$$
\text { Petugas kesehatan yang masih }
$$
merokok sebaiknya terus berusaha mengurangi konsumsi rokok sampai suatu saat bisa berhenti. Untuk manajemen Puskesmas Kediri I Tabanan agar segera menetapkan puskesmas sebagai kawasan bebas rokok.

\section{Daftar Pustaka}

1. Kurniawan, Bagus. Kematian Akibat Merokok, Indonesia Tempati Peringkat Ketiga Dunia. 2009. diakses tanggal 6 Januari 2011 tersedia dalam http://www.detiknews. com/ read/ 2009/05/29/173401/1139487/10/kemat ian-akibat-merokok-indonesia-tempatiperingkat-ketiga-di-dunia

2. Pusat Promkes. Lindungi Generasi Muda dari Bahaya Roko. diakses tanggal 16 Juni 2011 tersedia dalam : http://www.promosikesehatan.com/?ac $\mathrm{t}=$ news\& $\mathrm{id}=717$,

3. Hadi, MC., Sudiasih L., Suiraoka IP. Sikap Para Perokok di Bali dalam Menghadapi Kawasan Tapa Rokok, Laporan Penelitian Kerjasama Dinkes Prop.Bali dengan Poltekkes Depkes Denpasar ; 2006.

4. Depkes RI. Inmenkes RI No.459 tahun 1999 tentang Kawasan Bebas Rokok pada Sarana Kesehatan ; 1999. diakses tanggal 16 Juni 2011. tersedia dalam http://gizi.net/gaya-hidup/ PERMEN\%20KAWASAN\%20BEBA S\%20ROKOK. htm.
5. Utarini, A., Winkvist, A. and Ulfa, F.M. Rapid Assessment Procedures of Malaria in Low Endemic Countries : Community Perception in Jepara District, Indonesia.Social Science \& Madecine 56 ; 2003 p. 701-712.

6. Hudelson, P.M. Qualitative Research for Health Programmes. Geneva : WHO Division of Mental Health ; 1994. p. 12

7. Higginbotham, Albrecht G. and Connor L. Health Social Science A Transdisciplinary and Complexity Perspective. New York : Oxford University Press ; 2001.p. 235-238.

8. Sutopo, HB.Metode Penelitian Kualitatif Dasar Teori dan Terapannya dalam Penelitian, Surakarta : Universitas Sebelas Maret Edisi kedua ; 2006. h.130, , Surakarta.

9. Sitepoe, M. Kekhususan Rokok di Indonesia. Jakarta : Gramedia Widiasarana Indonesia ; 2000.

10. Muninjaya, AAG. (2004), Manajemen Kesehatan, Jakarta : Penerbit Buku Kedokteran EGC edisi 2 ; 2004. h.167. 